\title{
Newly emerged workers of the stingless bee Scaptotrigona aff. depilis prefer stored pollen to fresh pollen
}

\author{
Ayrton Vollet-Neto ${ }^{1}$, Camila Maia-Silva ${ }^{1,2}$, Cristiano Menezes $^{3,4}$, \\ Vera Lucia IMPERATRIZ-FONSECA ${ }^{1,2,5}$ \\ ${ }^{1}$ Faculdade de Filosofia, Ciências e Letras de Ribeirão Preto, Universidade de São Paulo, Avenida Bandeirantes 3900, \\ Ribeirão Preto, SP 14040-901, Brazil \\ ${ }^{2}$ Departamento de Ciências Animais, Universidade Federal Rural do Semi-Árido, Avenida Francisco Mota 572, \\ Mossoró, RN 59625-900, Brazil \\ ${ }^{3}$ Embrapa Amazônia Oriental, Travessa Dr. Enéas Pinheiro s/n, Belém, PA 66095-105, Brazil \\ ${ }^{4}$ Embrapa Meio Ambiente, Rodovia SP-340, Km 127,5, 13820-000, Jaguariúna, SP, Brazil \\ ${ }^{5}$ Instituto Tecnológico Vale, Rua Boaventura da Silva 955, Belém, PA 66055-090, Brazil
}

Received 1 December 2015 - Revised 4 July 2016 - Accepted 20 July 2016

\begin{abstract}
Like in honey bees, the pollen collected and stored by stingless bees usually undergoes a fermentation process characterized by increase in moisture, lactic acid, and proliferation of microorganisms. We tested whether 2day-old Scaptotrigona aff. depilis workers were more attracted to and consumed fermented pollen from old pollen pots ( $>7$ days) or fresh pollen collected from the corbicula of foragers. In each bioassay, we offered both types of pollen to 40 inexperienced workers of one colony for $24 \mathrm{~min}$, and repeated the procedure in ten different colonies. In all cases, there were more bees feeding on the fermented pollen, which was 2.2 times more consumed than the fresh pollen. Our results suggested that fermented pollen attracted more bees potentially due to innate preference of young bees, higher levels of attractant substances present in fermented pollen, or due to associative learning reminiscent from larvae feeding habits.
\end{abstract}

stingless bee nutrition / pollen microorganisms / pollen fermentation

\section{INTRODUCTION}

Stingless bees (Apidae, Meliponini), like honey bees (Apidae, Apini), are a group of social bees with perennial colonies (Wilson 1971). For colony growth and development, forager bees collect pollen as main protein source (Michener 1974). To ensure a constant food supply and, consequently, increase the colony's chances of survival during events of resource scarcity, bees store pollen and nectar (carbohydrate source) in the nest (Roubik 1982; Maia-Silva et al. 2015).

Corresponding author: A. Vollet-Neto, ayrtonvollet@gmail.com

Manuscript Editor: James Nieh
During pollen collection on flowers, foragers agglomerate pollen grains in their corbicula using nectar or salivary secretions. This process facilitates pollen adhesion to the corbicula (Herbert and Shimanuki 1978; Leonhardt et al. 2007). Vásquez and Olofsson (2009) observed bacteria from the honey stomach of honey bees in newly collected pollen as well as in pollen stored in the nest, which suggests that worker bees may inoculate microorganisms in the pollen during collection on flowers.

Inside the nest of honey bees and also in some stingless bees species, the stored pollen undergoes chemical and biological processes during storage that may change its chemical composition. The main biochemical reaction is fermentation into lactic acid in the stored pollen, which requires the presence of sugars for occurring (Testa et al. 1981; Vásquez and Olofsson 2009; Menezes et al. 2013). 
Some microorganisms are present in the pollen collected and stored by honey bees Apis mellifera, especially bacteria of the genera Streptococcus, Bifidobacterium, and Lactobacillus (Pain and Maugenet 1966; Gilliam 1979; Vásquez and Olofsson 2009) and some yeasts, which increase their population during storage (Pain and Maugenet 1966). Compared to honey bees, data on symbiotic microorganisms in colonies of stingless bees are scarce. There is evidence for the presence of microorganisms in pollen stored by stingless bees (Machado et al. 1971), but their influence or function is poorly understood (Menezes et al. 2013).

Although fermentation is relatively common in colonies of social bees, it is poorly known why it occurs. It is still not clear whether fermentation increases the nutritional benefits of pollen for workers because studies are not completely conclusive (Herbert and Shimanuki 1978) and due to the lack of investigation on this issue. Some studies indicate that the nutritional quality of honey bee pollen might be increased by fermentation (Gilliam 1997), therewith increasing longevity (Cremonez et al. 1998) and hemolymph protein levels (Herbert and Shimanuki 1978) of workers compared to bees feeding on fresh pollen. However, fermentation did not influence digestibility of pollen grains and hypopharyngeal gland development in honey bees (Herbert and Shimanuki 1978) and stingless bees (Fernandes-da-Silva and Serrao 2000). Additionally, no difference was found in nutritional composition of both types of honey bee pollen (Herbert and Shimanuki 1978). A second possibility is that the fermentation might prevent pollen decay, since the primary function of pollen storage, most likely, is the availability of this resource inside the colony in times of food scarcity in the field (Herbert and Shimanuki 1978; Fernandes-da-Silva and Serrao 2000; Anderson et al. 2011; Anderson et al. 2014). In this case it worth considering that fermentation could cause no advantage for bee health, or even carry some costs, which could be overcome by food availability throughout scarcity periods.

Newly emerged workers feed on pollen relatively early in their lives (Michener 1974; Sakagami 1982), a behavior that is likely linked to hypopharingeal glands development (CruzLandim et al. 2000). These glands are involved in the production of larval food (Sakagami 1982). Workers feed on pollen directly from the pots, which they have to find inside the dark nests probably based on olfactory cues. The attractiveness to a specific food source can reflect learning and/or innate preferences specially linked to olfactory signals (Waldbauer and Friedman 1991). Fresh pollen, recently collected by foraging bees on flowers, has a slight sweetish odor and flavor. Nevertheless, the fermentation process modifies considerably the odor, flavor, color, and texture of stored pollen (Menezes et al. 2013). Some stingless bees, such as Melipona and Scaptotrigona species, store moist and sour pollen (Menezes et al. 2013). Due to presence of higher levels of odor on stored pollen from fermented process, we asked whether the newly emerged workers could recognize these odors, causing a differential attraction to each type of pollen (fresh and fermented). In this study we used stingless bee specie, Scaptotrigona aff. depilis, as our model to investigate the attractiveness of newly emerged workers to the fermented versus non-fermented pollen.

\section{MATERIAL AND METHODS}

\subsection{Study site and model species}

The present study was conducted at the campus of the University of São Paulo at Ribeirão Preto, Brazil. We chose $S$. aff. depilis Moure 1942 (Apidae, Meliponini) as study model, which stores pollen in oval pollen pots of approximately 2 to $3 \mathrm{~cm}$ in height made of wax and resin. The selection of this species was based on our previous knowledge on pollen fermentation inside their nests (Menezes et al. 2013).

\subsection{Experimental setup}

For the experiments, we collected worker bees from the oldest brood combs of $S$. aff. depilis colonies (10 colonies). We used tweezers to open the oldest cells containing individual bees close to emergence and waited for $2 \mathrm{~h}$ until the adults emerged by themselves. The worker bees remained in Petri dishes for 2 days until the start of the experiment. During this period, the 
bees were fed only with energetic food (sugar water solution of 1:1 in mass).

For preparing the diet composed of non-fermented, fresh pollen $(\mathrm{NFe})$, we collected fresh pollen from the corbicula of foragers. Fermented pollen $(\mathrm{Fe})$ was taken from a closed pollen pot inside the colony. The pollen could be recognized as already fermented owing to its pasty aspect and acid odor, respectively. The pollen takes over 1 week to obtain this aspect (Menezes et al. 2013). We collected both diets from the same colonies as the newly emerged worker bees.

To assess whether worker bees prefer fermented pollen $(\mathrm{Fe})$ or non-fermented pollen $(\mathrm{NFe})$, we performed bioassays (10 repetitions; each repetition with bees from a different colony), in which we offered approximately $2000 \mathrm{mg}$ of each diet placed in small transparent plastic Petri dishes $(3 \mathrm{~cm}$ diameter $\times 0.7$ height) during $24 \mathrm{~min}$ to 40 newly emerged worker bees ( 2 days old). The bioassays were performed within cleaned Petri dishes $(15 \mathrm{~cm}$ diameter $\times 2 \mathrm{~cm}$ height). The fresh pollen was offered without any processing, remaining as pollen pellets which commonly crushed and turned into powder (we observed bees feeding on both types), and the fermented pollen was offered as a small pile, since it is pasty. We counted the number of worker bees feeding on fermented pollen and nonfermented pollen in the first minute, the third minute and, thereafter, at $3 \mathrm{~min}$ intervals, totalizing nine counts per colony. We weighted both diets before and after the bioassays in order to determine the total amount of pollen consumed from each diet type.

\subsection{Statistical analysis}

The potential effect of diets ( $\mathrm{Fe}$ and $\mathrm{NFe}$ ) on the choice of work bees was evaluated using Two-Way Repeated Measures ANOVA (Tukey test for post-hoc pairwise comparisons). We analyzed whether diet type (factor 1, Diet: $\mathrm{Fe}$ and $\mathrm{NFe}$ ), time (factor 2, Time: 1 to $24 \mathrm{~min}$ ), or the interaction between both (Diet $\times$ Time) accounted for potential variations in the distribution of worker bees between diets. To approach normality, data were transformed using a logarithmic transformation $X^{\prime}=\log (X+1)$ (Zar 1999). The total amount of pollen consumed from each diet type ( $\mathrm{Fe}, \mathrm{NFe}$ ) was compared using a Paired $t$ test. Statistical tests were performed using the software SigmaPlot for Windows 12.5 (Systat
Software Inc., USA). The significance level was $\alpha=$ 0.05 . Throughout the text and in the figures, data are presented as arithmetical mean \pm 1 st standard deviation.

\section{RESULTS}

Young $S$. aff. depilis workers showed a significant preference for fermented pollen $(\mathrm{Fe})$ over non-fermented pollen ( $\mathrm{NFe}$ ) (Figure 1). The food choice of the bees was significantly influenced by the diet type (Two-Way Repeated Measures ANOVA: factor 1, Diet: $F=25.0, P<0.001$, df $=$ $1)$. In the first minute, the number of bees feeding on both diets was low, but increased over time. Due this fact, we found a significant difference in the number of bees feeding on $\mathrm{Fe}$ or on $\mathrm{NFe}$ between the first minute, and the ninth, and twelfth minute, respectively (Two-Way Repeated Measures ANOVA: factor 2, Time, $F=2.9, P=0.007, \mathrm{df}=8$; Tukey Test: $\min 1$ vs. $\min 9: P=0.002$; $\min 1$ vs. $\min 12$ : $P=0.019$ ). We found no significant influence concerning the interaction of both factors (Two-Way Repeated Measures ANOVA: Diet $\times$ Time, $F=1.3, P=$ 0.249 , df $=8$ ) (Figure 1). The total amount of diet consumed was significantly higher for fermented pollen $(22.7 \pm 11.0 \mathrm{mg})$ than for nonfermented pollen $(8.9 \pm 7.4 \mathrm{mg})$ (Paired $t$ test: $t=$ 3.13, $P=0.012$ ) (Figure 2a).

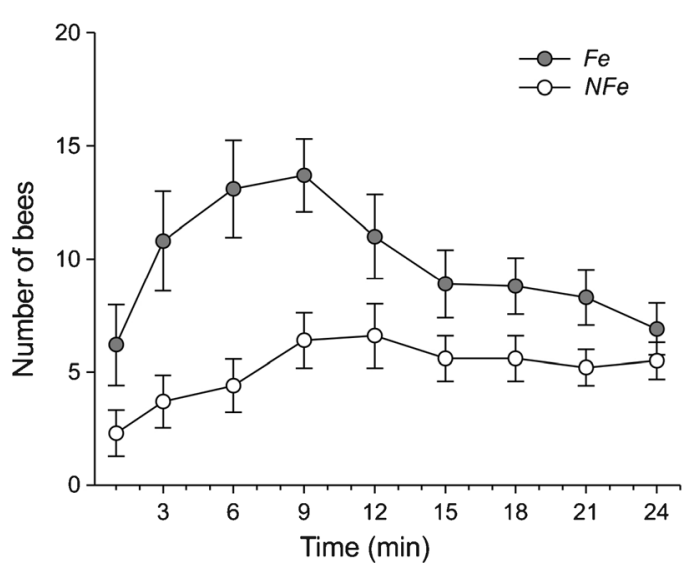

Figure 1. Number of worker bees feeding on fermented $\mathrm{Fe}$ ) and non-fermented pollen ( $\mathrm{NFe}$ ) during the period of observation. 

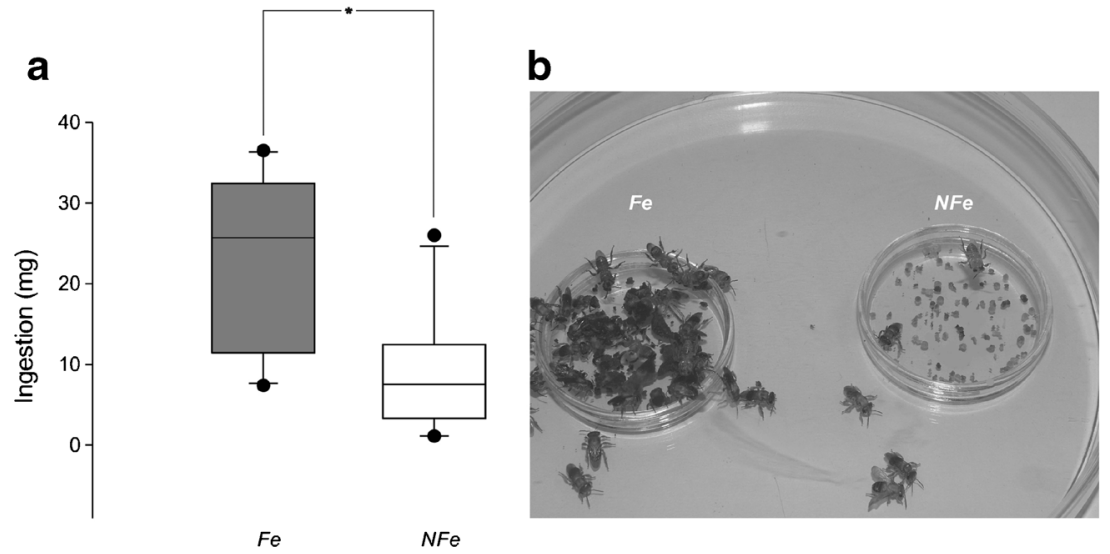

Figure 2. Ingestion of fermented $(\mathrm{Fe})$ and non-fermented pollen $(\mathrm{NFe})$. a The total amount of pollen consumed from each diet type ( $\mathrm{Fe}$ and $\mathrm{NFe}$ ). In the boxplots, the central line represents the median, the boxes represent the quartiles, the whiskers represent the $80 \%$ range, and the dots represent outliers. Asterisks indicate a statistically significant difference between groups. b Worker bees feeding on fermented $(\mathrm{Fe})$ and non-fermented pollen $(\mathrm{NFe})$.

\section{DISCUSSION}

Our results show that young bees of $S$. aff. depilis are significantly more attracted to fermented pollen than to fresh pollen (Figure $2 b$ ). The reasons for this preference include the possibility of (i) innate preferences of young bees to fermented pollen; (ii) the presence of higher levels of attractant substances in fermented pollen; and (iii) associative learning of larvae during their development due to constant exposition to fermented pollen in the larval food.

If fermentation would bring any benefit to the fitness of the workers that feed on fermented pollen or to the colony, then it is expected that natural selection would drive workers' preference towards fermented pollen. Fernandes-da-Silva and Serrão (2000) found no differences in pollen digestibility and hypopharingeal gland size when comparing the effect of fresh and stored pollen given to newly emerged worker of Scaptotrigona postica. Even without direct evidence of benefits from feeding on fermented pollen, the possibility of other effects on bees' health, which were not investigated so far, should be considered. Several other aspects of development, such as longevity, larval development, or increase in immunological defense of worker bees, may be affected by feeding on fermented pollen. Some microorganisms and their secondary metabolites can improve bee health by acting against infectious microorganisms (Herbert and
Shimanuki 1978; Gilliam 1997). Pettis et al. (2013) found that worker honey bees are more infected by the gut pathogen Nosema ceranae when feeding on pollen with high fungicide loads. Their results indicate that the fungicide affects microorganisms present in stored pollen and/or in honey bee workers' gut, consequently affecting their health. Similarly, Menezes et al. (2015) suggested that the fungus Monascus sp., which grows inside brood cells of $S$. aff. depilis, could be important for larval health. However, hard evidence for this assumption is still missing.

The workers' preference for fermented pollen could also be related the presence of other attractive substances, such as glucose. During pollen collection at flowers, foragers add nectar (sugars) to the pollen to increase adhesion of the pollen load to the corbicula (Herbert and Shimanuki 1978; Leonhardt et al. 2007). Moreover, fermented stored pollen could present higher sugar levels due to possible addition of nectar or honey prior to storage. This could make the fermented pollen odor more attractive to young bees. However, the newly emerged bees were fed ad libtum with sugar syrup before the experiment (see Methods section) and were supposedly looking for pollen sources during the experiment.

Fermentation could be neutral in terms direct advantages to workers, neither increasing nor decreasing pollen quality (or at least changes in different aspects could be equally costly or beneficial). In 
this case, fermentation could still help in the preservation of pollen, a hypothesis that has already been suggested by many authors and received great support from recent studies on honey bees (Herbert and Shimanuki 1978; Fernandes-da-Silva and Serrao 2000; Anderson et al. 2011; Anderson et al. 2014). In this case, it is not expected that workers would be more attracted to fermented pollen, since there would be no benefits on feeding on fermented pollen. However, chemical substances present in fermented pollen only could be used as cues to find the pollen inside the colony, and during the presented bioassay could have attracted the starving young bees directly to the fermented pollen, possibly masking the odor of fresh pollen source.

Some species of stingless bees, e.g., Ptilotrigona lurida (Camargo et al. 1992), Tetragonisca angustula, and Frieseomellita varia (Menezes et al. 2013; personal observation), apparently do not ferment their pollen. The absence of pollen fermentation in those stingless bees suggests that fermentation could be linked to pollen preservation, as species that do not ferment their pollen frequently store dehydrated pollen (Camargo et al. 1992). Dehydration is related to conservation, as microorganisms need water to develop (Menezes et al. 2013). Therefore, there might be a selective pressure for the conservation of pollen in perennial colonies. Pollen availability is seasonal in many tropical and subtropical areas (Aleixo et al. 2014), so long-term pollen storage could be advantageous. Moreover, this process is even more important in regions with severe scarcity of pollen during some periods of the year (Maia-Silva et al. 2015). Several studies provide evidence for the preservative properties of fermentation, including its use in the industry, such as in food preservation (Gilliam 1997).

The elevated attraction to fermented pollen in $S$. aff. depilis could also be due to the formation of the olfactory neural system during larval stages, since young larvae are constantly exposed to fermented pollen during their feeding stages. In contrast to the progressively feeding honey bees, in stingless bees the larval food is massively provided by workers which also seal off the cells after queen egg laying. Inside these brood cells, larvae have all necessary food to develop into adult bees (Michener 1974). Consequently, the larvae are submitted to fermented pollen throughout their entire development. This constant contact with fermented pollen in stingless bees might influence the formation of specific neural networks due to the synaptic plasticity already observed in brain centers of the honey bees olfactory system during their development (Oleskevich et al. 1997). In honey bees, there is evidence that exposure to odors during larval stages might affect adult physiology and behavior. Ramírez et al. (2016) showed that larvae reared in colonies fed with 1hexanol had differential proboscis extension response and neural plasticity as young adults. However, honey bee workers are not able to learn floral scents during pupal stages (Sandoz et al. 2000). This suggests that the influence of odor substances during preimaginal stages might be linked to an intimate contact with such substances, like feeding on it. Indeed, several adult holometabolous insects shows a strong preference for oviposit on plants at which they fed during their larval stages (Blackiston et al. 2008; Anderson et al. 2013; Prager et al. 2014), showing that there is associative learning during larval stages.

The modulation of the olfactory neural system has already been investigated in a stingless bee species of the same genus, Scaptotrigona pectoralis. Foragers submitted to scents present in floral fragrances inside their hives showed higher preferences for feeding on artificial feeders which also had the fragrances nearby (Reichle et al. 2010). Similar results were found in another social bee species, such as honey bees (Gil and De Marco 2005; Grüter et al. 2006; Farina et al. 2007) and Bombus terrestris (Molet et al. 2009). Associative learning in stingless bees is poorly investigated, especially regarding the effect of the larvae stimuli during their development. Rearing larvae in larval food containing different scents could provide the condition for testing this effect. Therefore, assuring the link between larval diet and food preferences still remains to be tested. One possibility to test this assumption would be to restrict the diet of nurse workers that feed on larvae with either fermented or fresh pollen. The pollen preference of newly emerged workers resulting from such feeding differences could be then tested using similar methods described here.

Our results show that newly emerged workers of $S$. aff. depilis prefer fermented over fresh pollen. In 
a similar experiment, Anderson et al. (2014) observed that worker honey bees (A. mellifera) prefer to consume fresh $(<72 \mathrm{~h})$ than stored ( $>96 \mathrm{~h})$ pollen. The authors suggested that the preference of worker honey bees for fresh pollen could be explained by a selective pressure related to a quick turnover of the nutrients most readily available in fresh pollen into living tissue reservoirs, like fat bodies. These nutrients would be better protected against microbial digestion, could be easily shared among colony members, and easier to digest than stored pollen. Differences in selective pressures to which both species are submitted, such as seasonality and microbial fauna, could be responsible for explaining the differences observed in our results. Our findings provide important information for stingless bees beekeeping, suggesting the necessity of fermenting artificial diets substitutes of pollen to increase its attractiveness.

\section{ACKNOWLEDGMENTS}

We would like to thank University of São Paulo for the facilities to study the stingless bee's colonies. We thank Prof. Fernando Sérgio Zucoloto (FFCLRP-USP) for suggestions that improved our bioassays and Prof. David De Jong (FMRP-USP) for helpful discussions. We also thank the two anonymous referees for their suggestions that substantially increased the quality of this manuscript. This study complies with current Brazilian laws and was financially supported by FAPESP (Fundação de Amparo à Pesquisa do Estado de São Paulo, 2012/11144-0 to AVN) and Coordenação de Aperfeiçoamento de Pessoal de Nível Superior (CAPES/PNPD to CMS).

Les ouvrières de l'abeille sans aiguillon Scaptotrigona aff. depilis venant d'émerger préfèrent le pollen stocké au pollen frais

nutrition / Meliponini / microorganismes du pollen / fermentation du pollen

Frisch geschlüpfte Arbeiterinnen der stachellosen Biene Scaptotrigona aff. depilis bevorzugen eingelagerten Pollen gegenüber frischen Pollen

Ernährung stachelloser Bienen / PollenMikroorganismen / Pollen-Fermentation

\section{REFERENCES}

Aleixo, K.P., de Faria, L.B., Groppo, M., do Nascimento Castro, M.M., da Silva, C.I. (2014) Spatiotemporal distribution of floral resources in a Brazilian city: implications for the maintenance of pollinators, especially bees. Urban For. Urban Gree 13 (4), 689-696

Anderson, K. E., Sheehan, T. H., Eckholm, B.J., Mott, B. M., De Grandi-Hoffman (2011) An emerging paradigm of colony health: microbial balance of the honey bee and hive (Apis mellifera ). Insectes Soc. 58, 431444

Anderson, P., Sadek, M.M., Larsson, M., Hansson, B.S., Thöming, G. (2013) Larval host plant experience modulates both mate finding and oviposition choice in a moth. Anim. Behav. 85, 1169-1175

Anderson, K.E., Carroll, M.J., Sheehan, T., Mott, B.M., Maes, P., Corby-Harris, V. (2014) Hive-stored pollen of honey bees: many lines of evidence are consistent with pollen preservation, not nutrient conversion. Mol. Ecol. 23 (23), 5904-5917

Blackiston, D.J., Casey, E.S., Weiss, M.R. (2008) Retention of memory through metamorphosis: can a moth remember what it learned as a caterpillar? PLoS One 3 (3), e1736

Camargo, J.M.F.D., Garcia, M.V.B., Junior, E.R.Q., Castrillon, A. (1992) Short notes on the bionomics of Ptilotrigona lurida (Hymenoptera, Apidae, Meliponinae): association of yeasts in stored pollen. Boletim do Museu Paraense Emilio Goeldi Serie Zoologia 8(2), 391-395

Cremonez, T.M., De Jong, D., Bitondi, M.M.G. (1998) Quantification of hemolymph proteins as a fast method for testing protein diets for honey bees (Hymenoptera: Apidae). J. Econ. Entomol. 91, 1284-1289

Cruz-Landim, C., Costa, R.A.C., Silva-De-Moraes, R.L.M. (2000) Hypopharyngeal gland function, glandular cell senescence and gland reactivation in bees. In: Austin, A.D., Dowton, M. (eds.) Hymenoptera: evolution, biodiversity and biological control, pp. 50-55. Csiro Publishing, Melbourne

Farina, W.M., Grüter, C., Acosta, L., Mc Cabe, S. (2007) Honey bees learn floral odors while receiving nectar from foragers within the hive. Naturwissenschaften 94 (1), 55-60

Fernandes-da-Silva, P.G., Serrao, J.E. (2000) Nutritive value and apparent digestibility of bee-collected and beestored pollen in the stingless bee, Scaptotrigona postica Latr. (Hymenoptera, Apidae, Meliponini). Apidologie 31, 39-45

Gil, M., De Marco, R.J. (2005) Olfactory learning by means of trophallaxis in Apis mellifera. J. Exp. Biol. 208 (4), 671-680

Gilliam, M. (1979) Microbiology of pollen and bee bread: the yeasts. Apidologie 10(1), 43-53

Gilliam, M. (1997) Identification and roles of nonpathogenic micro flora associated with honey bees. FEMS Microbiol Lett. 155 (1), 1-10 
Grüter, C., Acosta, L.E., Farina, W.M. (2006) Propagation of olfactory information within the honey bee hive. Behav. Ecol. Sociobiol. 60 (5), 707-715

Herbert, E.W., Shimanuki, H. (1978) Chemical composition and nutritive-value of bee-collected and bee-stored pollen. Apidologie 9 (1), 33-40

Leonhardt, S., Dworschak, K., Eltz, T., Bluthgen, N. (2007) Foraging loads of stingless bees and utilization of stored nectar for pollen harvesting. Apidologie 38 (2), 125-135

Machado, J.O. (1971) Simbiose entre as abelhas sociais brasileiras (Meliponinae, Apidae) e uma espécie de bactéria. Ciência e Cultura. 23, 625-633

Maia-Silva, C., Hrncir, M., Silva, C.I., Imperatriz-Fonseca, V.L. (2015) Survival strategies of stingless bees (Melipona subnitida) in an unpredictable environment, the Brazilian tropical dry forest. Apidologie 46, 631-643

Menezes, C., Vollet-Neto, A., Contrera, F.A.F.L., Venturieri, G.C., Imperatriz-Fonseca, V.L. (2013) The role of useful microorganisms to stingless bees and stingless beekeeping. In: Vit, P., Pedro, S.M., Roubik, D.W. (eds.) Pot-honey: a legacy of stingless bees, pp. 153-171. Springer, New York

Menezes, C., Vollet-Neto, A., Marsaioli, A.J., Zampieri, D., Fontoura, I.C., Luchessi, A.D., Imperatriz-Fonseca, V.L. (2015) A Brazilian social bee must cultivate fungus to survive. Curr. Biol. 25 (21), 2851-2855

Michener, C.D. (1974) The social behavior of the bees. Harvard University Press, Massachusetts

Molet, M., Chittka, L., Raine, N.E. (2009) How floral odours are learned inside the bumblebee (Bombus terrestris ) nest. Naturwissenschaften 96 (2), 213-219

Oleskevich, S., Clements, J.D., Srinivasan, M.V. (1997) Long-term synaptic plasticity in the honey bee. J. Neurophysiol. 78 (1), 528-532

Pain, J., Maugenet, J. (1966) Recherches biochimiques et physiologiques sur le pollen emmagasiné par les abeilles. Ann. Abeille 9, 209-236
Pettis, J.S., Lichtenberg, E.M., Andree, M., Stitzinger, J., Rose, R. (2013) Crop pollination exposes honey bees to pesticides which alters their susceptibility to the gut pathogen Nosema ceranae. PLoS One 8(7), e70182

Prager, S.M., Esquivel, I., Trumble, J.T. (2014) Factors influencing host plant choice and larval performance in Bactericera cockerelli. PLoS One 9 (4), e94047

Ramírez, G., Fagundez, C., Grosso, J.P., Argibay, P., Arenas, A., Farina, W.M. (2016) Odor experiences during preimaginal stages cause behavioral and neural plasticity in adult honeybees. Front. Behav. Neurosci. $\mathbf{1 0}, 105$

Reichle, C., Jarau, S., Aguilar, I., Ayasse, M. (2010) Recruits of the stingless bee Scaptotrigona pectoralis learn food odors from the nest atmosphere. Naturwissenschaften 97 (5), 519-524

Roubik, D.W. (1982) Seasonality in colony food storage brood production and adult survivorship: studies of Melipona in tropical forest (Hymenoptera: Apidae). J. Kansas Entomol. Soc. 55, 789-800

Sakagami, S.F. (1982) Stingless bees. In: Hermann, H.R. (ed.) Social insects, vol. 3, pp. 361-423. Academic, New York

Sandoz, J.C., Laloi, D., Odoux, J.F., Pham-Delègue, M.H. (2000) Olfactory information transfer in the honey bee: compared efficiency of classical conditioning and early exposure. Anim. Behav. 59(5), 1025-1034

Testa, P.R., Silva, A.N., Zucoloto, F.S. (1981) Nutritional value of different pollen mixtures for Nannotrigona (Scaptotrigona) postica . J. Apic. Res. 20, 94-96

Vásquez, A., Olofsson, T.C. (2009) The lactic acid bacteria involved in the production of bee pollen and bee bread. J. Apic. Res. 48, 189-195

Waldbauer, G.P., Friedman, S. (1991) Self-selection of optimal diets by insects. Annu. Rev. Entomol. 36, 43-63

Wilson, E.O. (1971) The insect societies. Belknap Press of Harvard University Press, Cambridge

Zar, J.H. (1999) Biostatistical analysis. Prentice Hall Inc., Upper Saddle River 